\title{
Treatment gap and help-seeking for postpartum depression in a rural African setting
}

Telake Azale ${ }^{1,2^{*}}$, Abebaw Fekadu ${ }^{2,3}$ and Charlotte Hanlon ${ }^{2,4}$

\begin{abstract}
Background: Postpartum depression (PPD) affects more than one in ten women and is associated with adverse consequences for mother, child and family. Integrating mental health care into maternal health care platforms is proposed as a means of improving access to effective care and reducing the 'treatment gap' in low- and middle-income countries. This study aimed to determine the proportion of women with PPD who sought help form a health facility and the associated factors.
\end{abstract}

Methods: A community based, cross-sectional survey was conducted in southern Ethiopia. A total of 3147 women who were between one and 12 months postpartum were screened for depressive symptoms in their home using a culturally validated version of the Patient Health Questionnaire (PHQ-9). Women scoring five or more (indicating potential depressive disorder) $(n=385)$ were interviewed regarding help-seeking behavior. Multiple logistic regression was used to identify factors associated independently with help-seeking from health services.

Results: Only $4.2 \%$ of women $(n=16)$ with high PPD symptoms had obtained mental health care and only $12.7 \%$ of women $(n=49)$ had been in contact with any health service since the onset of their symptoms. In the multivariable analysis, urban residence, adjusted odds ratio (aOR): 4.39 (95\% confidence interval (Cl) 1.23, 15.68); strong social support, aOR: 2.44 (95\% Cl 1.30, 4.56); perceived physical cause, aOR: 6.61 (95 \% Cl 1.76, 24.80); perceived higher severity aOR: 2.28 (95 \% Cl 1.41, 5.47); perceived need for treatment aOR: 1.46 (95 \% Cl 1.57, 18.99); PHQ score, aOR: 1.14 (95\% Cl 1.04, 1.25); and disability, aOR: 1.06 (95\% Cl 1.01, 1.15) were associated significantly with help-seeking from health services.

More than half of the women with high levels of PPD symptoms ( $n=231 ; 60.0 \%)$ attributed their symptoms to a psychosocial cause and 269 (69.9\%) perceived a need for treatment. Equal proportions endorsed biomedical treatment and traditional or religious healing as the appropriate intervention.

Conclusion: In the absence of an accessible maternal mental health service the treatment gap was very high. There is a need to create public awareness about PPD, its causes and consequences, and the need for help seeking. However, symptom attributions and help-seeking preferences indicate potential acceptability of interventions located in maternal health care services within primary care.

\footnotetext{
* Correspondence: telakea@yahoo.com

${ }^{1}$ Department of Health Education and Behavioral Sciences, University of

Gondar, College of Medicine and Health Sciences, Institute of Public Health,

Gondar, Ethiopia

${ }^{2}$ Department of Psychiatry, Addis Ababa University, College of Health

Sciences, Addis Ababa, Ethiopia

Full list of author information is available at the end of the article
} 


\section{Background}

Postpartum depression (PPD) is the most prevalent mental disorder in the perinatal period in high-income countries (HICs), affecting around 10 to $15 \%$ of women [1]. The prevalence of PPD appears to be at least as high in low- and middle-income countries (LMICs), affecting an estimated $19.8 \%[2]$, although estimates range from zero to $73.7 \%$ [3, 4]. Children born to women with PPD in LMICs are at higher risk of adverse impacts on health, growth and development $[5,6]$ but have lower access to evidence-based mental health care $[7,8]$.

Worldwide, at least $56 \%$ of people with non-postpartum depression are estimated to remain untreated $[9,10]$. Half of depressed individuals do not seek professional help and up to two-thirds remain untreated or receive inappropriate or inadequate treatment [11]. For PPD the treatment gap appears to be higher than for non-postpartum depression, with studies in HICs indicating that less than a quarter of women with PPD obtain professional help [12, 13]. Exploratory studies have indicated that social norms about good mothering, practical difficulties in accessing care with a young baby and low recognition of symptoms by the woman, her family and healthcare providers may act as specific barriers to accessing mental health care in the post-partum period in HICs [14-16]. The treatment gap for PPD has been little-investigated in LMICs but is expected to be higher than that found in HICs.

In response to this high treatment gap, there has been a global initiative to expand mental health care for perinatal women by integrating interventions into existing maternal health care [17, 18]. Stepped care models of mental health care and contextualized psychosocial interventions have been demonstrated to be feasible, acceptable and effective in the treatment of PPD in LMICs $[19,20]$, although most studies have been conducted in middle-income rather than low-income countries. However, further studies are needed to understand how these interventions can be scaled up in the highly diverse settings that exist in LMICs. To be successful, scale-up initiatives need to be mindful of the existing help-seeking behaviors and preferences of perinatal women with mental health problems. Understanding current help-seeking may give vital information about existing resources which can be integrated into any planned service; for example, about the potential for collaboration with traditional and faith healers [21].

Help-seeking for postpartum depression has not been studied quantitatively in LMICs. Qualitative exploration indicates that sociocultural factors [22] and causal attributions such as economic difficulty and poor marital relations [23] may be barriers to help-seeking for PPD. In Ethiopia, the period of postpartum confinement, which ranges from 40 days to three months, may be a barrier to help-seeking for women experiencing mental distress
[24]. In a previous qualitative study from rural Ethiopia key informants expressed the view that women would be exposed to attack by evil spirit and shamed if they left their home during the postpartum period [25]. In the same study, attribution of mental distress to an exacerbation of preexisting problems, such as poverty and marital discord, rather than to an illness indicated a further barrier to help-seeking from formal health care services [25].

To the best of our knowledge, there is no published study of the treatment gap and help seeking behavior for PPD conducted in a representative population sample in a LMIC setting. Therefore, this study aimed to (1) determine the proportion of women who obtained mental health care for symptoms of PPD, and (2) identify helpseeking behavior and preferences for source of help to inform development of a socioculturally acceptable service intervention for women with PPD.

\section{Methods}

Study design: a population-based cross-sectional survey. Study area: the study was carried out in Sodo district, Gurage Zone, Southern Nations, Nationalities and Peoples Region (SNNPR) of Ethiopia. Sodo is located about $100 \mathrm{~km}$ south of the capital city, Addis Ababa. In the most recent census, the population was estimated to be 161,952 persons (79,356 men; 82,596 women), with $88 \%$ of the population residing in rural areas [26]. Amharic is the official language in the district, but the second language for the majority of inhabitants. Within Sodo district, there are eight primary care health centers, each linked to health posts which are staffed by community-based health extension workers.

The nearest psychiatric out-patient service is located in Butajira town, $30 \mathrm{~km}$ away from the capital of the Sodo district. At the time of the study there were no specialist mental health professionals located within the district and no health care personnel trained in mental health care. However, as part of the Program for Improving Mental health carE (PRIME), plans were being made to integrate mental health care into primary care and maternal health care settings across the district [27]. PRIME is a multi-country project involving five LMICs (Ethiopia, India, Nepal, South Africa and Uganda). PRIME aims to generate evidence on the best approaches for the integration of mental health care into the existing primary and maternal health care services. This study was conducted to inform possible models of intervention for maternal mental health care within the PRIME service model.

\section{Sampling}

As part of PRIME, a census of all households in the district was conducted. However, only 1427 infants (aged 
less than one year) were recorded within the census, a figure which was much lower than the estimated population from the Central Statistics Agency [28]. Second, we used the immunization report for under one year children from the district health office. Third, we checked the registry of pregnant and postpartum women which is compiled and maintained by community-based health extension workers. Finally, the data collectors identified eligible women in a house-to-house search. These combined approaches resulted in the identification of 3147 women between one and 12 months postpartum. All the identified women were screened using the Patient Health Questionnaire, 9-item depression scale (PHQ-9) [29] and women scoring five or more on the PHQ-9 formed the sample for the study presented in this paper.

\section{Measures}

Postpartum depressive symptoms were measured using the PHQ-9. The PHQ-9 was developed originally to measure depression in primary care settings [30]. The PHQ-9 has been culturally validated for use in several African country settings [31-35] including in postpartum women in rural Ghana [36] and in the primary health care context in rural Ethiopia [37]. In the latter Ethiopian study of the criterion validity of the PHQ-9, a score of five or more was found to have a sensitivity of $83 \%$ and specificity of $75 \%$ for the detection of major depressive disorder.

\section{Help-seeking behavior}

This was assessed using the General Help Seeking Questionnaire (GHSQ) [38]. The GHSQ is a 9-item instrument that was developed to assess future intentions to seek help from a list of culturally-relevant sources. We adapted the GHSQ to ask about actual (rather than intended) behavior and collapsed the response categories to yes/no. The sources of help included in the GHSQ are classified into two major classes: formal and informal. Formal help-seeking includes visiting health professionals (e.g., psychiatrists, psychologists, general practitioners, nurses, etc) or traditional and faith healers [38]. In a rural Ethiopian context, this was adapted to be 'general health worker' or 'mental health worker'. Informal help-seeking is defined as talking about one's symptoms with parents, friends, a partner or other relative.

The woman's explanatory model of postpartum depressive symptoms was investigated using the Short Explanatory Model Interview (SEMI) [39]. The SEMI is a semi-structured questionnaire with open ended questions to be documented verbatim and coded using a contextualized set of possible categories. A version of SEMI was adapted for Ethiopia with an expert consensus meeting involving mental health professionals and qualitative researchers with experience working in the study site. The women's perceptions of causes, severity, treatment needs and options for symptoms of postpartum depression were assessed.

Disability was measured using the World Health Organization Disability Assessment Tool (WHODAS) [40] which covers the functional domains of understanding and communicating, getting around, self-care, getting along with people, life activities, and participation in society. Each item was scored from 1 (none) to 5 (extreme or cannot do), with the total WHODAS score ranging from 36 to 180. The WHODAS has been used in Ethiopia in perinatal women in the neighboring district and found to have convergent validity and acceptability [41].

Social support was measured using the Oslo Social Support Scale (OSSS-3) [42] The OSSS-3 total score ranges between three and 14. Scores from 3 to 8 are considered to indicate poor support, scores from 9 to 11 indicate intermediate support, and a score between 12 and 14 is considered to indicate strong social support. Although these cut-off points have not been validated in the Ethiopian context, the OSSS-3 categories were used in a community study in the same Ethiopian district and showed good utility [43].

The Barriers to Access to Care Evaluation (BACE) was adapted for use in the study site [44]. Twenty-three out of 30 original items were used in this study as some of the items were not applicable for women with PPD living in a rural African context. For example items like "Concern that it might harm my chances when applying for jobs" and "Not wanting a mental health problem to be on my medical records" were excluded. The tool asks about a range of issues that have ever stopped, delayed or discouraged an individual from getting, or continuing with, professional care for a mental health problem on a scale from 0 (not at all) to 3 (a lot). The domains of potential barriers include individual perception (including stigma), infrastructure, knowledge, social support, attitude of respondents towards the available treatment and previous experiences.

\section{Data collection and quality assurance}

Women were interviewed in their homes privately by 36 trained data collectors who were trained for 9 days. The data collectors were recruited from the district and the sub-districts or, if no eligible person was available, applicants from the neighboring sub-districts were recruited. The educational levels of the data collectors ranged from tenth grade completed to first degree. They were supervised by four supervisors who were also trained and assisted by the investigators. The supervisors were diploma or degree graduates. The data collectors went house-to-house, explained the purpose of the research and either gave an information sheet to the woman or 
read the information for those who were unable to read. Women who consented to participate were interviewed at a time convenient for them within a day or two of initial contact. A pre-test was conducted in three subdistricts near the study area. Data were collected between April and June 2014.

\section{Data management and analysis}

Data were double entered into EpiData version 3.1 and exported to SPSS-20 for analysis. Frequencies, percentages, and mean values were used to describe the categorical and continuous variables. Bivariate analyses were carried out to investigate the association between helpseeking behavior of women with symptoms of PPD from a general health facility and each of the independent variables. This outcome was of interest because of the plan to integrate mental health care for women into general health services. All variables with a $p$-value $<0.2$ were included in the multivariable model. Adjusted odds ratios with associated $95 \%$ confidence intervals were reported in the final multiple logistic regression model.

\section{Results}

A total of 385 women with a PHQ-9 score of five or more were included in the analyses. Only one woman was excluded and referred for specialist mental health care after she was found to have probable psychotic symptoms. No women refused to participate in the study.

The prevalence of depression across the postpartum months was $12.7,11.2$, and $12.5 \%$ in the months one to three, four to six, and seven or more, respectively.

\section{Socio-demographic characteristics}

The mean PHQ score of the participants was 7.8 (Standard Deviation (SD) 3.0). The mean age of the respondents was 28.8 years (SD 5.2) years). Almost all women were married (97.1 \%; $n=374$ ) and rural residents (94.3\%; $n=363$ ). More than two-thirds, $(70.4 \% ; n=271)$ were unable to read and write. The vast majority $(94.8 \% ; n=365)$ were followers of Orthodox Christianity and $91.7 \%(n=353)$ were Gurage by ethnicity (See Table 1 ).

Half $(50.9 \% ; n=196)$ of the women were grandmultiparious. Just less than half $(44.4 \% ; n=171)$ of women perceived that their wealth was lower than their neighbors. More than a quarter, $(27 \% ; n=104)$ perceived that they had poor social support. For the married women, about $80 \%$ reported having a good relationship with their husband. However, $18.2 \%$ said that their husbands did not live with them, for example, because of working away from home $(12.5 \%)$ or due to having another wife (3.4\%). Nearly a quarter of women $(24.7 \% ; n=95)$ reported that their husbands drank too much alcohol.

Mild to extreme impairment was reported by 339 (88 \%) of women in one or more of the six domains of
Table 1 Socio-demographic characteristics of women with symptoms of postpartum depression in Sodo district, Ethiopia, $2014(n=385)$

\begin{tabular}{|c|c|c|}
\hline Socio-demographic characteristic & Frequency & Percent \\
\hline \multicolumn{3}{|l|}{ Age in years } \\
\hline Less than 20 & 28 & 7.3 \\
\hline $20-29$ & 174 & 45.2 \\
\hline $30-39$ & 175 & 45.5 \\
\hline 40 or above & 8 & 2.1 \\
\hline \multicolumn{3}{|l|}{ Marital status } \\
\hline Married & 374 & 97.1 \\
\hline Single/widowed/divorced & 11 & 2.9 \\
\hline \multicolumn{3}{|l|}{ Residence } \\
\hline Rural & 363 & 94.3 \\
\hline Urban & 22 & 5.7 \\
\hline \multicolumn{3}{|l|}{ Education } \\
\hline No formal education & 308 & 80.0 \\
\hline Formal education & 77 & 20 \\
\hline \multicolumn{3}{|l|}{ Occupation } \\
\hline House wife & 317 & 82.3 \\
\hline Private (shop, other trade) & 49 & 12.8 \\
\hline No job & 19 & 4.9 \\
\hline \multicolumn{3}{|l|}{ Religion } \\
\hline Orthodox & 365 & 94.8 \\
\hline Protestant & 12 & 3.1 \\
\hline Muslim & 6 & 1.6 \\
\hline Other & 2 & 0.6 \\
\hline \multicolumn{3}{|l|}{ Ethnicity } \\
\hline Gurage & 353 & 91.7 \\
\hline Oromo & 26 & 6.8 \\
\hline Amhara & 5 & 1.3 \\
\hline Other & 1 & 0.3 \\
\hline
\end{tabular}

functioning. However, only $2.6 \%$ reported that they had been unable to function for more than 15 days in the last one month due to disability.

\section{Help-seeking from general health care facilities}

Only 50 women $(12.9 \%)$ had ever had contact with health services following the onset of symptoms of PPD. Only $4.2 \%(n=16)$ reported that they accessed mental health care. From the informal sources of help, husbands were the most frequently sought source of help $(n=236$; $61.3 \%)$. The least frequently sought source of help was a sorcerer $(n=12 ; 3.1 \%)$ (See Table 2). Out of 276 (71.6\%) women who said that their illness needed treatment, 192 (49.9\%) endorsed modern medicine as their preferred type of treatment. 
Table 2 Frequency distribution of items of the General Help-seeking Questionnaire (GHSQ) among women with symptoms of postpartum depression $(n=385)$

\begin{tabular}{|c|c|c|}
\hline Sources of help & Number & Percent \\
\hline \multicolumn{3}{|l|}{ Formal } \\
\hline \multicolumn{3}{|c|}{ General health professional (any) } \\
\hline Yes & 49 & 12.7 \\
\hline No & 336 & 87.3 \\
\hline \multicolumn{3}{|c|}{ Mental health professional } \\
\hline Yes & 16 & 4.2 \\
\hline No & 369 & 95.8 \\
\hline \multicolumn{3}{|c|}{ Religious leader } \\
\hline Yes & 45 & 11.7 \\
\hline No & 340 & 88.3 \\
\hline \multicolumn{3}{|c|}{ Traditional healer } \\
\hline Yes & 20 & 5.2 \\
\hline No & 365 & 94.8 \\
\hline \multicolumn{3}{|c|}{ Sorcerer/witch doctor } \\
\hline Yes & 12 & 3.1 \\
\hline No & 373 & 96.9 \\
\hline \multicolumn{3}{|l|}{ Informal } \\
\hline \multicolumn{3}{|l|}{ Husband } \\
\hline Yes & 236 & 61.3 \\
\hline No & 149 & 38.7 \\
\hline \multicolumn{3}{|l|}{ Friends } \\
\hline Yes & 182 & 47.3 \\
\hline No & 203 & 52.7 \\
\hline \multicolumn{3}{|l|}{ Parents } \\
\hline Yes & 180 & 46.8 \\
\hline No & 205 & 53.2 \\
\hline \multicolumn{3}{|c|}{ Other relatives } \\
\hline Yes & 140 & 36.4 \\
\hline No & 245 & 63.6 \\
\hline
\end{tabular}

The perceived cause for 231 (60.0\%) of respondents was psychosocial, which included financial difficulty, an unsupportive partner and "thinking too much". The most frequently mentioned factors that helped PPD symptoms get better were performing religious activities (prayer, using holy water and attending church), discussing with significant others, or thinking less about the problem and being relaxed (be calm, sleep, take rest). The factors that were mentioned as aggravating PPD symptoms were work overload, psychological (persistent worry, thinking too much, upset), and interpersonal conflict. About two-thirds of women $(62.1 \% ; n=239)$ attributed their problem to internal events such as their failure to do something that they should have done or doing something they should not have done.
Thinking the problem would get better by itself (76.1\%; $n=293)$; the woman wanting to solve the problem by herself $(66.7 \% ; n=257)$; fear of cost $(56.0 \% ; n=216)$; and distance $(50.4 \% ; n=194)$ were identified as the most common barriers to accessing care. (See Figure 1).

In the multivariable model, urban residence, adjusted Odds Ratio (aOR): 3.76, 95 \% CI $(1.07,13.12)$; multiparity, aOR: 1.16, 95 \% CI (1.01, 1.33); perceived physical cause, aOR: $6.84,95 \% \mathrm{CI}(2.06,22.75)$; perceived severity, aOR: 3.10, $95 \%$ CI $(1.13,8.48)$; perceived need for treatment, aOR: 6.24, $95 \% \mathrm{CI}(1.82,21.35)$; PHQ score, aOR: $1.13,95 \%$ CI $(1.04,1.24)$ for every one point increase; and overall disability score on the WHODAS, aOR: $1.01,95 \%$ CI $(1.00,1.03)$ were found to be statistically significantly associated with help seeking behavior from a health facility.

The following self-reported barriers to care were associated with not seeking help from health services in the multivariable model: wanting to solve the problem by herself aOR: $0.51,95 \% \mathrm{CI}(0.30,0.88)$ and thinking that they did not have a problem aOR: 0.36, $95 \%$ CI $(0.18,0.71)$. Unexpectedly, concern about what friends may think or say was associated with increased help-seeking from health services: aOR: 2.45, $95 \%$ CI $(1.21,4.96)$ (Table 3).

\section{Discussion}

In this population-based survey of postpartum women with high levels of depressive symptoms in rural Ethiopia, the treatment gap for biomedical care was very high. Levels of help-seeking from any type of biomedical care provider were low $(12.7 \%)$ and only $4.2 \%$ of women $(n=15)$ accessed mental health care. Many women relied on non- professional sources of help such as from their partner, parents and friends. However, the majority $(69.9 \%)$ of women reported that they needed professional help for their symptoms, and equal proportions endorsed biomedical health care and traditional or religious healing.

The finding that one in ten women had been in contact with general health services since the onset of PPD symptoms does not indicate that these women would have been looking for, or received, mental health care. At the time of the study there was no mental health service within general health care facilities [45]. Instead, it is likely that somatic symptoms of depression were the motivating factor [46]. This accords with our finding that help-seeking from health services was higher in women who attributed their symptoms to a physical cause. There are no mental health professionals working within the district, and so it is noteworthy that $4.2 \%$ of women sought out mental health care from the psychiatric nurse-led out-patient clinic in the neighboring 


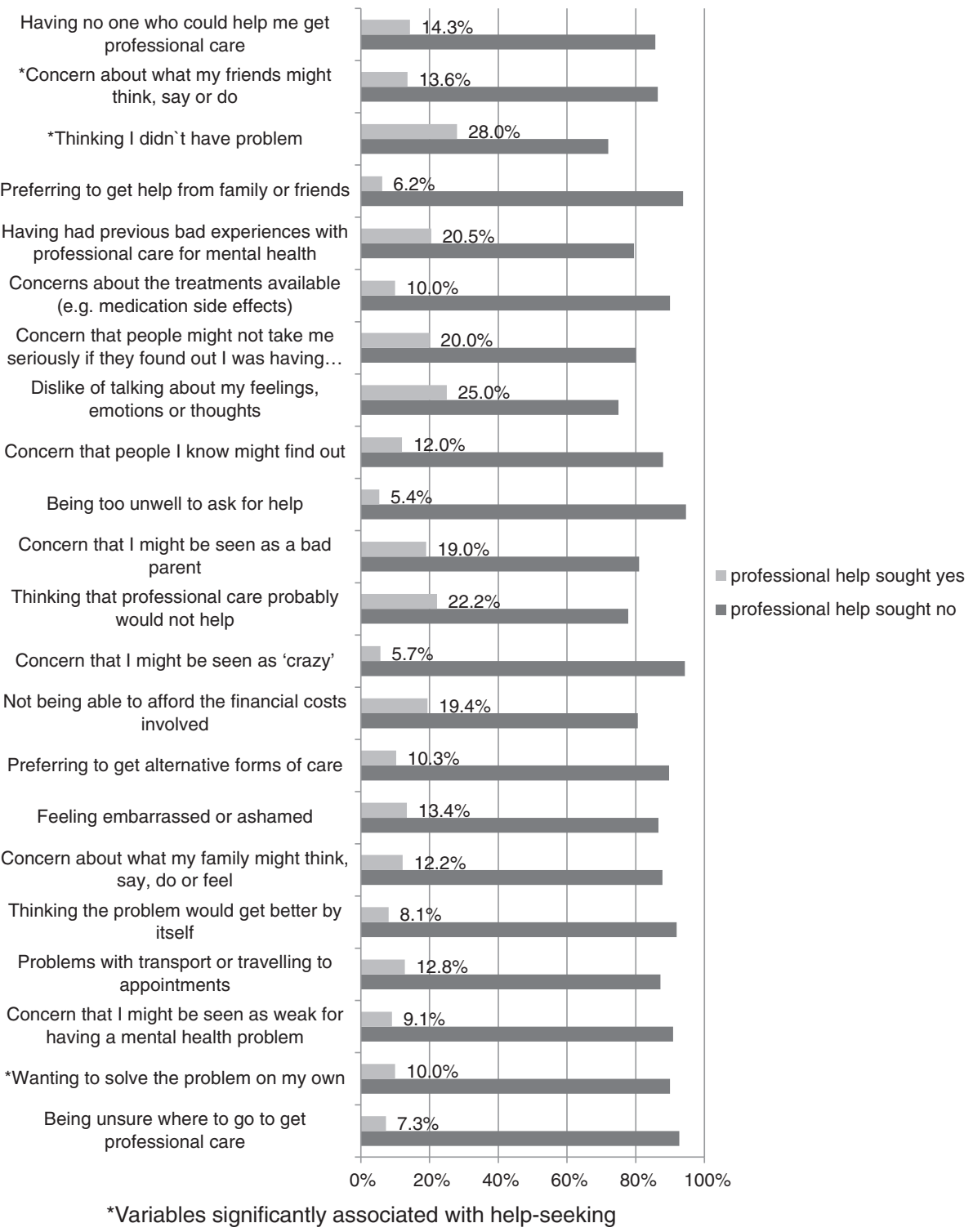

Fig. 1 The frequency of the 23 items of the Barriers to Access to Care Evaluation

district (30 to $50 \mathrm{~km}$ away). Indicators of severity of PPD (increasing number of depression symptoms, perceived severity and level of functional impairment) were all associated with higher levels of help-seeking from health services. This supports the notion that symptoms were troublesome for women and having an adverse impact upon their lives.

The willingness of $12 \%$ of women to seek help from health services, together with the further $49.8 \%$ who expressed a preference for biomedical care for their problem, indicates potential acceptability for plans to integrate mental health care into maternal health care platforms in this rural Ethiopian district. However, possible barriers to help-seeking from health services were also apparent in our study. Women from rural areas were less likely to seek help from health services, which may reflect a combination of factors, including proximity, level of autonomy and awareness of the potential benefits of treatment. Contrary to expectations, there was no association between indicators of socioeconomic status (e.g. experiencing hunger in the last one month, relative wealth) or educational status and help-seeking from health services. The limited variation in socio-economic status in rural communities may have contributed to this negative finding. More than $80 \%$ of the respondents did not receive formal education and are housewives by occupation. In line with many studies, perceived social support was associated with help seeking in this study [47-49]. Urban residence was associated with help seeking and is likely 
Table 3 Factors associated with help-seeking behavior from a health facility for postpartum depression symptoms at Sodo district, $2014(n=385)$

\begin{tabular}{|c|c|c|c|c|}
\hline \multirow[t]{2}{*}{ Characteristics } & \multicolumn{2}{|c|}{ Help-seeking from health facility } & \multirow[t]{2}{*}{ Crude odds ratio (95\% confidence interval) } & \multirow[t]{2}{*}{ AOR(95 \% Cl) } \\
\hline & Yes N (\%) & No N (\%) & & \\
\hline \multicolumn{5}{|l|}{ Socio-demographic factors } \\
\hline Age in years $($ mean $=28.8, S D=5.23)$ & & & $1.03(0.97,1.09)$ & $0.96(0.88,1.04)$ \\
\hline \multicolumn{5}{|l|}{ Residence } \\
\hline Rural & $42(11.6)$ & $321(88.4)$ & 1 & 1 \\
\hline Urban & $7(31.8)$ & $15(68.2)$ & $3.56(1.37,9.25)$ & $4.39(1.23,15.68)$ \\
\hline \multicolumn{5}{|l|}{ Education } \\
\hline No formal education & $38(12.3)$ & $270(87.7)$ & 1 & 1 \\
\hline Formal education & $11(14.3)$ & $66(85.7)$ & $0.84(0.41,1.74)$ & $0.97(0.37,2.52)$ \\
\hline \multicolumn{5}{|l|}{ Experienced hunger } \\
\hline Yes & $19(15.1)$ & $107(84.9)$ & $1.35(0.73,2.51)$ & $0.70(0.30,1.67)$ \\
\hline No & $30(11.6)$ & $229(88.4)$ & 1 & 1 \\
\hline \multicolumn{5}{|l|}{ Relative wealth } \\
\hline Lower & $22(12.9)$ & $149(87.1)$ & 1 & 1 \\
\hline Same or better & $27(19.3)$ & $187(80.7)$ & $1.02(0.56,1.86)$ & $0.56(0.05,5.36)$ \\
\hline \multicolumn{5}{|l|}{ Social support } \\
\hline Good & $34(28.8)$ & $247(71.2)$ & $2.65(1.38,5.11)$ & $2.44(1.30,4.56)$ \\
\hline Poor & $15(14.4)$ & 89 (85.6) & 1 & 1 \\
\hline \multicolumn{5}{|l|}{ Perceived cause } \\
\hline Psychosocial & $15(6.5)$ & $216(93.5)$ & $4.17(2.02,8.59)$ & $4.24(1.94,9.26)$ \\
\hline Physical & $20(22.5)$ & $69(77.5)$ & $8.64(2.76,27.00)$ & $6.61(1.76,24.80)$ \\
\hline Supernatural & $6(37.5)$ & $10(62.5)$ & $2.81(1.19,7.05)$ & $2.85(1.06,7.67)$ \\
\hline I don't know & $8(16.3)$ & $41(83.7)$ & 1 & 1 \\
\hline \multicolumn{5}{|l|}{ Perceived severity } \\
\hline Severe & $30(49.3)$ & $123(50.7)$ & $2.73(1.47,5.06)$ & $2.28(1.41,5.47)$ \\
\hline Not severe & $19(16)$ & $213(84)$ & 1 & 1 \\
\hline \multicolumn{5}{|l|}{ Perceived need for treatment } \\
\hline Yes & $46(17.1)$ & $223(82.9)$ & $1.77(2.36,25.53)$ & $1.46(1.57,18.99)$ \\
\hline No & $3(5.4)$ & $113(94.6)$ & 1 & 1 \\
\hline Want to solve problem self & $26(19.9)$ & $231(80.1)$ & $0.24(0.09,0.65)$ & $0.51(0.30,0.88)$ \\
\hline Professional care wouldn't help & $8(12.4)$ & $116(87.6)$ & $0.47(0.25,0.89)$ & $0.55(0.28,1.09)$ \\
\hline Thinking no problem & $9(11.7)$ & $142(88.3)$ & $0.38(0.20,0.72)$ & $0.36(0.18,0.71)$ \\
\hline Concern about what friends think & $17(42.3)$ & $78(57.7)$ & $2.90(1.70,4.94)$ & $2.45(1.21,4.96)$ \\
\hline PHQ score & & & $1.13(1.04,1.23)$ & $1.14(1.04,1.25)$ \\
\hline WHODAS Score & & & $1.45(1.03,2.05)$ & $1.06(1.00,1.15)$ \\
\hline
\end{tabular}

to be due to a better access of urban residents to health institutions and contact with health professionals for routine maternal and child health services. Education and knowledge about depression have been found to be facilitators of help seeking in some studies [50]. However, systematic reviews of help seeking interventions revealed that knowledge tends to improve attitudes but not behavior [51, 52], although education can create access to health service use through better information and income.
Some of the apparent "barriers" to help-seeking, for example, wanting to solve the problem on their own or not framing their symptoms as a problem, may reflect the attribution of PPD symptoms to social adversity, as was found in a qualitative study of PPD conceptualization in the neighboring district [25]. As a screening tool for depressive symptoms was used in this study, which has a relatively low positive predictive value [37], some of the women may be suffering from transient distress which 
does not meet diagnostic criteria for depression. Therefore caution needs to be exercised not to pathologize social suffering as depressive disorder in this setting. On the other hand, low levels of awareness about mental health conditions and their treatability may be a barrier to women who could otherwise benefit from biomedical treatment. Longitudinal evaluation of the outcomes for women with PPD who limit their help-seeking to friends and family, or who seek formal sector care from traditional and religious healers, is needed in order to understand whether a narrow view of 'evidence-based care' overstates the apparent 'treatment gap' in this setting. Only by providing evidence of the effectiveness, or otherwise, of the non-biomedical approaches to care for PPD can we fully understand the unmet needs for care; however, it was evident that there was a desire for help beyond that which had already been obtained within the sociocultural context.

The finding that women who endorsed "concern about what my friends might think, say, or do" if they attended a health facility (intended to tap into stigma) were actually significantly more likely to seek help from a health facility was unexpected. It seems probable that women interpreted this question as meaning that expression of concern from friends would increase attendance at a health facility. Most of the participants talked to their husbands and many sought help from parents, friends and other relatives. Those individuals who had discussed their problems with their significant others could be prompted to seek professional help if aware of the availability of care [48].

Among the several barriers to help seeking identified within the study, thinking that professional care wouldn't help, and thinking that they didn't have a problem requiring treatment were associated significantly with lower levels of help seeking from health facilities. This indicates low level of awareness about the potential benefits of biomedical treatments for PPD. Increasing mental health literacy within the population, including amongst husbands, may give women more choices about the care they seek. Furthermore, although not significant, fear of cost and distance from mental health care were frequently mentioned as barriers to help-seeking. Integrating maternal mental health care into primary health care services may, therefore, improve the uptake of mental health service.

The perception of women that psychosocial factors are the major contributors of their symptoms and their attribution to internal events might have led in their religious and emotion focused coping strategies that they mentioned as relieving factors of symptoms. This may help for the contextualization of psychosocial intervention that builds on things that women find to be helpful.

\section{Limitations}

The time frame for help seeking was not specified in the questionnaire. Although the participants were asked for the presence of PPD symptoms in the preceding two weeks, the symptoms might have been present for several months, including during pregnancy when most women were likely to have had contact with health professionals for antenatal care, and this could have inflated the estimates of contact with services. Another limitation is that no reliability testing was carried out for the coding of responses to the Short Explanatory Model Interview. A further limitation is that we do not know how women managed to access the existing mental health service in the neighboring district. Although we made strenuous efforts to ensure complete ascertainment of postpartum women, it is possible that we missed some women and this could have reduced the generalizability of the findings.

\section{Conclusion}

Help seeking from health professionals for symptoms of postpartum depression was very low in the study district. In the absence of an accessible maternal mental health service, the treatment gap for PPD was very high. However, symptom attributions and helpseeking preferences indicate potential acceptability of interventions located in maternal health care services within primary care. Creating public awareness about PPD, its causes and consequences, and the need for help seeking are necessary steps to support the integration of mental health into primary care-based maternal health care.

\section{Abbreviations}

BACE, Barriers to Access to Care Evaluation; CSA, Central Statistics Agency; GHSQ, General Help Seeking Questionnaire; HIC, high income country; LMIC, low and middle income country; OSSS, Oslo Social Support Scale; PHQ, patient health questionnaire; PPD, postpartum depression; PRIME, programme for improving mental health care; SEMI, short explanatory model interview; SNNPR, South Nations and Nationalities and Peoples Region; WHODAS, World Health Organization Disability Assessment Schedule

\section{Acknowledgements}

This document is an output from the PRIME Research Program Consortium which has been funded by UK Aid from the UK Government; however the views expressed do not necessarily reflect the UK Government's official policies. We would also like to acknowledge Sodo district health and administrative offices, the 58 sub-district administrative offices, the supervisors, and data collectors. We thank the study participants who took their time to respond for the questionnaire.

\section{Funding}

This document is an output from the PRIME Research Program Consortium which has been funded by UK Aid from the UK Government; however the views expressed do not necessarily reflect the UK Government's official policies.

\section{Availability of data and materials}

The data for this study are part of a PhD thesis for Telake Azale (due to be submitted by September 2016) and therefore cannot be made publically available at the present time. Through the PRIME consortium, data will be made publically available in due course. 


\section{Authors' contribution}

TA developed the study design, trained data collectors and supervisors supervised the data collection and data entry processes, analyzed the data, and prepared the draft manuscript. $\mathrm{CH}$ supervised TA in development of the study design, participated in data analysis, contributed to interpretation of findings and commented on the draft manuscript. AF provided supervision in development of the study design, and contributed to the interpretation and write-up of the findings. All authors approved the final version of the manuscript.

\section{Competing interests}

The authors declare that they have no competing interests.

\section{Consent for publication}

N/A.

\section{Ethics approval and consent to participate}

Ethical approval was obtained from the Institutional Review Board of the College of Health Sciences, Addis Ababa University. Permission was also obtained from the Sodo District Health Office. Women who agreed to participate gave written consent. For those who were not literate, independent witnesses were invited to sign to indicate that the information had been read out correctly. Non-literate participants then gave a finger print to indicate consent. Confidentiality was maintained by omitting identifiers from the computer and privacy was ensured during interview. Women who endorsed the PHQ item indicating suicidal ideation were linked to the Butajira hospital psychiatric nurse-led outpatient clinic. All participants were given an information sheet and were only included in the study after providing informed consent.

\section{Author details}

'Department of Health Education and Behavioral Sciences, University of Gondar, College of Medicine and Health Sciences, Institute of Public Health, Gondar, Ethiopia. ${ }^{2}$ Department of Psychiatry, Addis Ababa University, College of Health Sciences, Addis Ababa, Ethiopia. ${ }^{3}$ Department of Psychological Medicine, Centre for Affective Disorders, King's College London, Institute of Psychiatry, Psychology and Neuroscience, London, UK. 'King's College London, Institute of Psychiatry, Psychology and Neuroscience, Centre for Global Mental Health, London, UK.

\section{Received: 13 October 2015 Accepted: 27 May 2016} Published online: 10 June 2016

\section{References}

1. \O'Hara MW, Swain AM. Rates and risk of postpartum depression-a meta-analysis. Int Rev Psychiatry. 1996;8:37-54

2. Fisher J, Cabral de Mello M, Patel V, Rahman A, Tran T, Holton S, et al. Prevalence and determinants of common perinatal mental disorders in women in low- and lower-middle-income countries: a systematic review. Bull World Health Organ. 2012;90(2):139G-49. Epub 2012/03/17.

3. Gaynes BN, Gavin N, Meltzer-Brody S, Lohr KN, Swinson T, Gartlehner G, et al. Perinatal depression: prevalence, screening accuracy, and screening outcomes. Evid Rep Technol Assess (Summ). 2005;5(119):1-8. Epub 2005/03/12

4. Gavin NI, Gaynes BN, Lohr KN, Meltzer-Brody S, Gartlehner G, Swinson T. Perinatal depression: a systematic review of prevalence and incidence. Obstet Gynecol. 2005;106(5 Pt 1):1071-83. Epub 2005/11/02.

5. Stein A, Pearson RM, SH G, Rapa E, Rahman A, McCallum M, et al. Effects of perinatal mental disorders on the fetus and child. Lancet. 2014;384(9956): 1800-19.

6. Surkan PJ, Kennedy CE, Hurley KM, Black MM. Maternal depression and early childhood growth in developing countries: systematic review and metaanalysis. Bull World Health Organ. 2011;89(8):608-15. Epub 2011/08/13.

7. Baron E, Field S, Kafaar Z, Honikman S. Patterns of use of a maternal mental health service in a low-resource antenatal setting in South Africa. Health Soc Care Community. 2014 [Epub ahead of print].

8. O'Mahony J, Donnelly T. Immigrant and refugee women's post-partum depression help-seeking experiences and access to care: a review and analysis of the literature. J Psychiatr Ment Health Nurs. 2010;17(10):917-28. Epub 2010/11/17.

9. Kohn R, Saxena S, Levav I, Saraceno B. The treatment gap in mental health care. Bull World Health Organ. 2004;82(11):858-66. Epub 2005/01/11.
10. Twomey CD, Prince M, Cieza A, Baldwin DS, Prina MA. Cross-sectional associations of depressive symptom severity and functioning with health service use by older people in Low-and-middle income countries. Int J Environ Res Public Health. 2015;12:3774-92.

11. Bijl RV, de Graaf R, Hiripi E. The prevalence of treated and untreated mental disorders in five countries. Health Aff. 2003:22(3):122-33.

12. Bina R. Seeking help for postpartum depression in the Israeli Jewish Orthodox Community: factors associated with use of professional and informal help. Women Health. 2014;54(5):455-73.

13. Mclntosh J. Postpartum depression: women's help-seeking behaviour and perceptions of cause. J Adv Nurs. 1993;18(2):178-84. Epub 1993/02/01.

14. Bilszta J, Ericksen J, Buist A, Milgrom J. Women's experience of postnatal depression - beliefs and attitudes as barriers to care. Aust $J$ Adv Nurs. 2008;27(3):44-54.

15. Abrams LS, Dornig K, Curran L. Barriers to service use for postpartum depression symptoms among low-income ethnic minority mothers in the United States. Qual Health Res. 2009:19(4):535-51. Epub 2009/03/21.

16. Dennis CL, Chung-Lee L. Postpartum depression help-seeking barriers and maternal treatment preferences: a qualitative systematic review. Birth. 2006; 33(4):323-31. Epub 2006/12/08

17. WHO. Global action plan for the prevention and control of noncommunicable diseases 2013-2020 Geneva. Geneva: World Health Organization; 2013.

18. Rahman A, Surkan PJ, Cayetano CE, Rwagatare P, KE D. Grand challenges: integrating maternal mental health into maternal and child health programmes. PLoS Med. 2013;10(5):e1001442.

19. Clarke K, King M, Prost A. Psychosocial interventions for perinatal common mental disorders delivered by providers who are not mental health specialists in low- and middle-income countries: a systematic review and meta-analysis. PLoS Med. 2013:10(10):e1001541. Epub 2013/11/10.

20. Chowdhary N, Sikander S, Atif N, Singh N, Ahmad I, Fuhr DC, et al. The content and delivery of psychological interventions for perinatal depression by nonspecialist health workers in low and middle income countries: a systematic review. Best Pract Res Clin Obstet Gynaecol. 2014;28(1):113-33. Epub 2013/09/24

21. Selamu M, Asher L, Hanlon C, Medhin G, Hailemariam M, Patel V, et al. Beyond the biomedical: community resources for mental health care in rural Ethiopia. PLoS One. 2015 [Epub ahead of print].

22. Dejman M, Ekblad S, Forouzan AS, Baradaran-Eftekhari M, Malekafzali H. Explanatory model of help-seeking and coping mechanisms among depressed women in three ethnic groups of Fars, Kurdish, and Turkish in Iran. Arch Iran Med. 2008;11(4):397-406. Epub 2008/07/01.

23. Rodrigues M, Patel V, Jaswalc S, dS N. Listening to mothers: qualitative studies on motherhood and depression from Goa, India. Soc Sci Med. 2003; 57:1797-806.

24. Berhane $Y$, Gossaye $Y$, Emmelin M, Hogberg U. Women's health in a rural setting in societal transition in Ethiopia. Soc Sci Med. 2001;53:1525-39.

25. Hanlon C, Whitley R, Wondimagegn D, Alem A, Prince M. Postnatal mental distress in relation to the sociocultural practices of childbirth: An exploratory qualitative study from Ethiopia. Soc Sci Med. 2009:69:1211-9.

26. FDRE, PCC. Summary and statistical report of the 2007 population and housing census: Population size by age and sex. Addis Ababa: Population Census Policy; 2008

27. Lund C, Tomlinson M, De Silva M, Fekadu A, Shidhaye R. PRIME: a programme to reduce the treatment Gap for mental disorders in five Lowand middle-income countries. PLoS Med. 2012;9(12):e1001359.

28. CSA. Population projection of Ethiopia for all regions at wereda level from 2014 - 2017. Addis Ababa: Central Statistical Agency; 2013.

29. Kroenke K, AD M. Common symptoms in ambulatory care: incidence, evaluation, therapy, and outcome. Am J Med. 1989;86:262-6.

30. Kroenke K, Spitzer RL, Williams JB. The PHQ-9: validity of a brief depression severity measure. J Gen Intern Med. 2001;16(9):606-13. Epub 2001/09/15.

31. Adewuya AO, Ola BA, Afolabi OO. Validity of the patient health questionnaire (PHQ-9) as a screening tool for depression amongst Nigerian university students. J Affect Disord. 2006:96(1-2):89-93. Epub 2006/07/22.

32. Chen $\mathrm{S}$, Chiu H, Xu B, Ma Y, Jin T, Wu M, et al. Reliability and validity of the PHQ-9 for screening late-life depression in Chinese primary care. Int J Geriatr Psychiatry. 2010;25(11):1127-33. Epub 2009/12/24

33. de Lima Osorio F, Vilela Mendes A, Crippa JA, Loureiro SR. Study of the discriminative validity of the PHQ-9 and PHQ-2 in a sample of Brazilian women in the context of primary health care. Perspect Psychiatr Care. 2009; 45(3):216-27. Epub 2009/07/02 
34. Gjerdingen D, Crow S, McGovern P, Miner M, Center B. Postpartum depression screening at well-child visits: validity of a 2-question screen and the PHQ-9. Ann Fam Med. 2009;7(1):63-70. Epub 2009/01/14.

35. Zhong Q, Gelaye B, Fann JR, Sanchez SE, Williams MA. Cross-cultural validity of the Spanish version of PHQ-9 among pregnant Peruvian women: a Rasch item response theory analysis. J Affect Disord. 2014; 158:148-53. Epub 2014/03/25.

36. Weobong B, Akpalu B, Doku V, Owusu-Agyei S, Hurt L, Kirkwood B, et al. The comparative validity of screening scales for postnatal common mental disorder in Kintampo, Ghana. J Affect Disord. 2009;113(1-2):109-17.

37. Hanlon C, Medhin G, Selamu M, Breuer E, Worku B, Hailemariam M, et al. Validity of brief screening questionnaires to detect depression in primary care in Ethiopia. J Affect Disord. 2015;186:32-9.

38. Wilson CJ, Deane FP, Ciarrochi F. Measuring help-seeking intentions: properties of the general help-seeking questionnaire. Can J Couns. 2005;39(1):15-28.

39. Lioyd RK, Jacob KS, Patel V. The development of the Short Explanatory Model Interview(SEMI) and its use among primary care attendees with common mental disorders: a preliminary report. Psycol Med. 1988; 28:1231-37.

40. WHO. In: CAS, editor. World Health Organization Disability Assessment Schedule (WHODAS)-II. Geneva: Whorld Health Organization; 2000.

41. Senturk V, Hanlon C, Medhin G, Dewey M, Araya M, Alem A, et al. Impact of perinatal somatic and common mental disorder symptoms on functioning in Ethiopian women: The P-MaMiE population-based cohort study. J Affect Disord. 2012;136(3):340-9.

42. Dalgard OS, Dowrick C, Lehtinen V, Vazquez-Barquero IL, Casey P, Wilkinson G. Negative life events, social support and gender difference in depression: a multinational community survey with data from the ODIN study. Soc Psychiatry Psychiatr Epidemiol. 2006;41(6):444-51.

43. Fekadu A, Rane L, Wooderson SC, Markopoulou K, Poon L, Cleare AJ. Prediction of longer-term outcome of treatment-resistant depression in tertiary care. Br J Psychiatry. 2012;201:369-75.

44. Clement S, Brohan E, Jeffery D, Henderson C, Hatch SL, Thornicroft G. Development and psychometric properties the Barriers to Access to Care Evaluation scale (BACE) related to people with mental ill health. BMC Psychiatry. 2011;12:36.

45. Hanlon C, Luitel NP, Kathree T, Murhar V, Shrivasta S, Medhin G, et al. Challenges and opportunities for implementing integrated mental health care: a district level situation analysis from five low- and middle-income countries. PLoS One. 2014;9(2):e88437. Epub 2014/02/22.

46. Senturk V, Hanlon C, Medhin G, Dewey M, Araya C, Alem A, et al. Impact of perinatal somatic and common mental disorder symptoms on functioning in Ethiopian women: The P-MaMiE population-based cohort study. J Affect Disord. 2011;136(3):340-9.

47. Gulliver A, Griffiths KM, Christensen H. Barriers and facilitators to mental health help-seeking for young elite athletes: a qualitative study. BMC Psychiatry. 2012;12:157. Epub 2012/09/27.

48. Vogel $\mathrm{DL}$, Wade $N G$, Wester $\mathrm{SR}$, Larson L, Hackler AH. Seeking help from a mental health professional: the influence of one's social network. I Clin Psychol. 2007;63(3):233-45. Epub 2007/01/11.

49. Vega WA, Kolody B, Aguilar-Gaxiola S. Help seeking for mental health problems among Mexican Americans. J Immigr Health. 2001;3(3):133-40. Epub 2005/10/18.

50. Buist A, Speelman C, Hayes B, Reay R, Milgrom J, Meyer D, et al. Impact of education on women with perinatal depression. J Psychosom Obstet Gynaecol. 2007;28(1):49-54. Epub 2007/04/25.

51. Costin DL, Mackinnon AJ, Griffiths KM, Batterham PJ, Bennett AJ, Bennett K, et al. Health e-cards as a means of encouraging help seeking for depression among young adults: randomized controlled trial. J Med Internet Res. 2009; 11(4):e42. Epub 2009/10/24.

52. Gulliver A, Griffiths KM, Christensen H, Brewer JL. A systematic review of help-seeking interventions for depression, anxiety and general psychological distress. BMC Psychiatry. 2012;12:81.

\section{Submit your next manuscript to BioMed Central and we will help you at every step:}

- We accept pre-submission inquiries

- Our selector tool helps you to find the most relevant journal

- We provide round the clock customer support

- Convenient online submission

- Thorough peer review

- Inclusion in PubMed and all major indexing services

- Maximum visibility for your research

Submit your manuscript at www.biomedcentral.com/submit
() BioMed Central 